\title{
Intraneostriatal Administration of Glutamate Antagonists Increases Behavioral Activation and Decreases Neostriatal Ascorbate via Nondopaminergic Mechanisms
}

\author{
R. Christopher Pierce and George V. Rebec \\ Program in Neural Science, Department of Psychology, Indiana University, Bloomington, Indiana 47405
}

Behavioral findings suggest that the effects of neostriatal glutamate and ascorbate are opposed to those of neostriatal dopamine. Recent evidence also indicates that glutamate and ascorbate are linked via a carrier-mediated heteroexchange process, suggesting that ascorbate may act through the glutamate system to influence behavior. In order to assess glutamate-ascorbate interactions and their influence on the behavioral output of the basal ganglia, glutamate and homocysteic acid (a glutamate reuptake blocker) as well as NMDA antagonists were infused into the neostriatum of freely moving rats while extracellular neostriatal ascorbate was monitored via electrochemically modified carbon-fiber electrodes. Neostriatal 3,4-dihydroxyphenylacetic acid (DOPAC), a major dopamine metabolite, also was recorded in order to assess the dependency of any drug effect on the nigrostriatal dopamine system. Intraneostriatal infusions of L-glutamate $(1 \mu \mathrm{g} / \mu \mathrm{l})$, but not L-homocysteic acid $(30 \mu \mathrm{g} / \mu \mathrm{l})$, elevated extracellular neostriatal ascorbate levels. Neither of these drugs had any effect on neostriatal DOPAC or overt behavioral activity. Intraneostriatal infusion of the noncompetitive NMDA antagonist dizocilpine (MK-801; $3 \mu \mathrm{g} / \mu \mathrm{l})$ or the competitive NMDA antagonist 3-(2-carboxypiperazin-4yi)-propyl-1-phosphonene (CPPene; $5 \mu \mathrm{g} / \mu \mathrm{l}$ ) decreased neostriatal ascorbate but had no effect on neostriatal DOPAC. Both dizocilpine and CPPene activated behavior in intact and sham-lesioned animals as well as in animals with near-total depletions of neostriatal dopamine following a 6-hydroxydopamine Iesion. When administered systemically, however, dizocilpine $(1.0 \mathrm{mg} / \mathrm{kg})$ significantly increased neostriatal DOPAC. This effect appears to be regulated via midbrain NMDA receptors, in that this effect was completely abolished by electrolytic lesions of the substantia nigra pars reticulata. In addition, systemic dizocilpine substantially lowered the level of extracellular ascorbate (in both intact/sham and substantia nigra-lesioned animals), but subsequent intraneostriatal infusions of glutamate increased ascorbate levels to the same extent as that observed in undrugged animals.

Taken together, these results suggest that neostriatal NMDA receptors regulate basal, but not glutamate-stimulat-

Received Jan. 27, 1993; revised Mar. 26, 1993; accepted Apr. 13, 1993.

This research was supported, in part, by NSF Grant BNS 91-12055. We thank Paul Langley for expert technical assistance and Faye Caylor for helping with manuscript preparation.

Correspondence should be addressed to George V. Rebec, Program in Neural Science, Department of Psychology, Indiana University, Bloomington, IN 47405. Copyright (C) 1993 Society for Neuroscience $0270-6474 / 93 / 134272-09 \$ 05.00 / 0$ ed, increases in neostriatal ascorbate and also induce behavioral hyperactivity through nondopaminergic mechanisms. Conversely, NMDA antagonist-induced increases in nigrostriatal dopamine synthesis, as reflected through changes in neostriatal DOPAC, appear to be regulated by NMDA receptors located in the substantia nigra. These results provide support for a functional link between neostriatal glutamate and ascorbate and suggest that neostriatal glutamate release inhibits the behavioral output of the basal ganglia.

[Key words: ascorbate, glutamate, NMDA, dizocilpine, CPPene (3-(2-carboxypiperazin-4-yl)-propyl-1-phosphonene), DOPAC, homocysteic acid, in vivo voltammetry, neostriatum]

Converging evidence suggests multiple interactions between ascorbate and glutamate in the neostriatum. At the presynaptic level, ascorbate appears to be colocalized with glutamate in corticoneostriatal neurons, and the release of these substances is mediated by a complex heteroexchange process at the axon terminal. Thus, lesions of this pathway markedly deplete both neostriatal ascorbate (Basse-Tomusk and Rebec, 1990) and glutamate (Walaas, 1981; Hassler et al., 1982; Young and Bradford, 1986), whereas glutamate infusions into the neostriatum increase neostriatal ascorbate release and this process is blocked by glutamate reuptake blockers (O'Neill et al., 1984; Cammack et al., 1991; Ghasemzadeh et al., 1991). Moreover, because glutamate receptor antagonists have been reported to have no effect on glutamate-induced increases in neostriatal ascorbate (Cammack et al., 1991), glutamate-induced neostriatal ascorbate release appears to be regulated via glutamate reuptake sites rather than presynaptic glutamate receptors. Postsynaptically, ascorbate and glutamate appear to interact in their influence on neostriatal neuronal activity. Iontophoretic application of ascorbate and glutamate, for example, activates a much larger proportion of neostriatal neurons than iontophoresis of ascorbate alone (Gardiner et al., 1985). It seems likely, therefore, that endogenous glutamate regulates increases in neostriatal ascorbate release, while ascorbate appears to modulate neostriatal neuronal activity, especially in the presence of glutamate.

Ascorbate and glutamate also have been shown to regulate behavior. Thus, both systemic (Tolbert et al., 1979; Rebec et al., 1985) and intraneostriatal (White et al., 1990) administration of ascorbate attenuates the behavioral response to the indirect dopamine agonist amphetamine while ascorbate potentiates the catalepsy produced by the dopamine antagonist haloperidol (Rebec et al., 1985; Dorris and Dill, 1986). Fur- 
thermore, repeated coadministrations of ascorbate and haloperidol potentiate the supersensitive behavioral response to the direct dopamine agonist apomorphine typically observed following treatment with haloperidol alone (Pierce et al., 1991). Although the mechanisms underlying these behavioral changes remain to be determined, it seems clear that ascorbate modulates dopamine-induced behavioral activation.

The recent development of selective glutamate antagonists has greatly aided the assessment of the effects of central glutamate systems on behavior. Thus, systemic administration of the noncompetitive NMDA antagonist dizocilpine (MK-801) induces locomotion and sniffing as well as motor ataxia (Koek et al., 1988; Ford et al., 1989; Lehmann-Masten and Geyer, 1991; Kretschmer et al., 1992). Because high doses of glutamate antagonists are known to increase neostriatal dopamine (Barbeito et al., 1990; Imperato et al., 1990; Leviel et al., 1990; Moghaddam and Gruen, 1991; Keefe et al., 1992), it was suggested that NMDA antagonists stimulate behavior through interactions with the dopamine system (Hiramatsu et al., 1989; Loscher and Honack, 1992). However, the doses of NMDA antagonists required to stimulate dopamine release may not reflect a primary action at the NMDA receptor (Moghaddam and Gruen, 1991; Keefe et al., 1992), and dizocilpine has been shown to stimulate motor responses in monoamine-depleted mice (Carlsson and Carlsson, 1990; Carlsson et al., 1991; Svensson et al., 1991). Furthermore, injection of the NMDA antagonist D,L-2-amino-5-phosphonovaleric acid (AP-5) directly into the nucleus accumbens of monoamine-depleted mice is known to induce locomotor activation (Svensson and Carlsson, 1992). Collectively, these findings suggest that striatal glutamate exerts an inhibitory influence on locomotion via nondopaminergic mechanisms (Carlsson and Carlsson, 1990).

Based on these lines of evidence, it appears that neostriatal ascorbate may act via glutamatergic mechanisms to influence behavioral activity. To test this hypothesis, we combined intraneostriatal infusions with voltammetric techniques to assess glutamate's control of neostriatal ascorbate release. We also assessed changes in extracellular 3,4-dihydroxyphenylacetic acid (DOPAC), a major dopamine metabolite, as an indirect measure of dopaminergic activity. All recordings were obtained from freely moving animals in order to relate ongoing changes in neostriatal ascorbate and DOPAC with behavioral activity. Our results indicate that NMDA antagonists regulate basal neostriatal ascorbate and also stimulate behavior through nondopaminergic mechanisms. Conversely, NMDA antagonist-induced increases in dopamine synthesis and release appear to be regulated by NMDA receptors located in the substantia nigra.

\section{Materials and Methods}

Animals. Adult, male, Sprague-Dawley rats (300-400 gm), bred in our animal colony, were used as subjects. They were housed individually under standard laboratory conditions with food and water available continuously. All animal use protocols followed guidelines established by the National Institutes of Health and were approved by the Indiana University Institutional Animal Care and Use Committee.

Surgery. Prior to surgery, all animals were anesthetized with Equithesin $(0.33 \mathrm{ml} / \mathrm{kg}$, i.p.); 6-hydroxydopamine (6-OHDA) rats were pretreated with the monoamine oxidase inhibitor pargyline $(40 \mathrm{mg} / \mathrm{kg}$, i.p.) and the norepinephrine reuptake blocker desipramine $(25 \mathrm{mg} / \mathrm{kg}$, i.p. $)$. All animals then were placed in a stereotaxic instrument, and a hole was drilled unilaterally through the skull over the neostriatum $(1.0 \mathrm{~mm}$ anterior and $2.5 \mathrm{~mm}$ lateral to bregma; Paxinos and Watson, 1982). For 6-OHDA lesions, a second hole was drilled over the medial forebrain bundle ( $4.0 \mathrm{~mm}$ posterior and $2.0 \mathrm{~mm}$ lateral to bregma), a cannula was lowered through this hole into the medial forebrain bundle $(8 \mathrm{~mm}$ ventral to the dura), and $2.0 \mu \mathrm{l}(4.0 \mu \mathrm{g} / \mu \mathrm{l})$ of 6-OHDA was infused over a $5 \mathrm{~min}$ period. After the infusion, the cannula remained in place for 5 min. For unilateral substantia nigra pars reticulata (SNR) lesions, an insulated tungsten electrode was lowered to the following coordinates relative to bregma: $2.5 \mathrm{~mm}$ lateral, $5.5 \mathrm{~mm}$ posterior, and $8.0 \mathrm{~mm}$ ventral. A $300 \mu \mathrm{A}$ DC current was administered for 2 min between the electrode tip (cathode) and an alligator clip (anode) attached to the fascia at the edge of the incision. After lesioning, the cannula or lesioning electrode then was removed and a plastic cylindrical hub, designed to mate with an electrode holder for voltammetric recordings (see Pierce et al., 1992b; Rebec et al., 1993), was centered over the hole above the neostriatum and cemented onto the skull. Control rats received the same treatment as lesion animals, including lowering the cannula or electrode into the brain, but no neurotoxin or current was administered. Following surgery, all animals were treated with $0.20 \mathrm{ml}(25 \mathrm{mg})$ of Rocephin (Roche) to minimize infection. Voltammetric recordings were performed after a recovery period of approximately $7 \mathrm{~d}$.

Voltammetry. Microvoltammetric electrodes were prepared from Thornell P-55 carbon fibers (Union Carbide) as described previously (Ewing et al., 1982; Kamata et al., 1986). The active electrode surface is $200 \mu \mathrm{m}$ in length with a $5 \mu \mathrm{m}$ radius. Each electrode was treated in a citrate-phosphate buffer solution by application of a triangular wave ( $70 \mathrm{~Hz}, 0.09-3.0 \mathrm{~V}$ vs a saturated calomel reference electrode) for 20 $\mathrm{sec}$ followed by $10 \mathrm{sec}$ of $0.5 \mathrm{~V}$ cathodal current, $3 \mathrm{sec}$ of $0.9 \mathrm{~V}$ anodal current, and $8 \mathrm{sec}$ of $1.5 \mathrm{~V}$ cathodal current. This treatment modifies the active surface of the electrode to allow discrimination of ascorbate from catechols and other easily oxidizable compounds (Gonon et al., 1980,1981 ). Each electrode was then tested with staircase voltammetry in a solution containing $100 \mu \mathrm{M}$ ascorbate and $20 \mu \mathrm{M}$ DOPAC until the response stabilized.

For in vivo voltammetry, the electrode was secured in a holder equipped with a stainless steel, luer-lock fitting that mates with the hub placed on the animal's skull during surgery. The holder includes a threaded assembly that allows the electrode to be raised and lowered through the brain (Pierce et al., 1992b; Rebec et al., 1993). The holder also contains a 33-gauge infusion cannula, which allows drugs to be administered close $(100-500 \mu \mathrm{m})$ to the active surface of the voltammetric electrode. The electrode and infusion cannula were lowered $5 \mathrm{~mm}$ ventral to the brain surface into the neostriatum. Generation of waveforms for staircase voltammetry and storage of sampled current was performed by a computer (IBM-XT) interfaced to a locally constructed potentiostat of conventional three-electrode design (Ewing et al., 1982). The carbonfiber served as the working electrode, while the stainless steel infusion cannula served as both the reference and auxiliary electrodes. A potential was applied to the working electrode in $6 \mathrm{mV}$ steps from -100 to +500 $\mathrm{mV}$ versus reference to ensure oxidation of ascorbate and DOPAC. Short pulses $(98 \mathrm{msec})$ were used to restrict sampling to the solution pool near the electrode surface. The scan rate was set at $20 \mathrm{mV} / \mathrm{sec}$; scans were obtained at $1 \mathrm{~min}$ intervals. Voltammograms display peaks representing ascorbate (approximately $150 \mathrm{mV}$ vs reference) and DOPAC (approximately $300 \mathrm{mV}$ vs reference), as well as a third more positive peak thought to represent 5 -hydroxyindoleacetic acid and uric acid (Cespuglio et al., 1981; Crespi et al., 1984).

Drug-induced changes in extracellular ascorbate were tested after a stable baseline was established for voltammetry and all animals were resting quietly. Separate groups of animals received infusions of L-glutamate $(1 \mu \mathrm{g} / \mu \mathrm{l})$, L-homocysteic acid $(10 \mu \mathrm{g} / \mu \mathrm{l})$, dizocilpine $(3 \mu \mathrm{g} / \mu \mathrm{l})$, 3-(2-carboxypiperazin-4-yl)-propyl-1-phosphonene (CPPene; $10 \mu \mathrm{g} / \mu \mathrm{l}$ ), or $0.9 \%$ saline. Dizocilpine and CPPene at these same doses also were infused into the neostriatum of unilaterally 6-OHDA-lesioned animals. The flow rate for all infusions was $10 \mu \mathrm{l} / \mathrm{hr}$. In all instances, the infusion lasted for the duration of the voltammetric recording period. The doses of these drugs when administered intrancostriatally arc known to produce either reliable increases in neostriatal ascorbate or characteristic patterns of locomotion and stereotyped behavior (R. C. Pierce and G. $\mathrm{V}$. Rebec, unpublished observations). In all cases, voltammetric recordings continued for another $50 \mathrm{~min}$. Dizocilpine also was systemically administered to intact, sham, and SNR-lesioned animals at a dose $(1 \mathrm{mg} / \mathrm{kg})$ known to increase behavioral activation and neostriatal DOPAC while decreasing neostriatal ascorbate (Pierce and Rebec, 1992). Fifty minutes following the systemic administration of dizocilpine to intact/sham animals, glutamate $(1 \mu \mathrm{g} / \mu \mathrm{l})$ was infused into the neostriatum and voltammetric signals were recorded for another $10 \mathrm{~min}$.

When voltammetric recording was completed, all animals were anesthetized with sodium pentobarbital. Some of the working electrodes used for each drug group were removed for postcalibration in a solution 
SALINE INFUSION

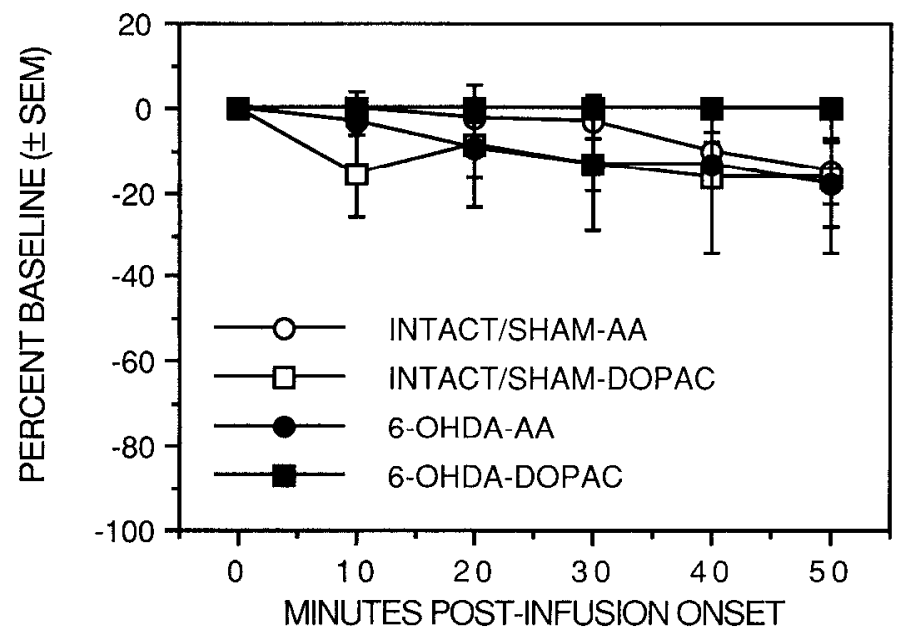

Figure 1. Effects of $0.9 \%$ saline infusion $(10 \mu \mathrm{l} / \mathrm{hr}$ for the duration of the experiment) into the neostriatum of intact/sham and 6-OHDAlesioned animals on neostriatal ascorbate $(A A)$ and DOPAC. The ascorbate and DOPAC responses are presented as the mean $( \pm$ SE) percentage predrug baseline. These responses served as the appropriate controls for drug infusions into intact/sham and 6-OHDA-lesioned animals, respectively.

containing $100 \mu \mathrm{M}$ ascorbate and $20 \mu \mathrm{M}$ DOPAC. In order to verify the recording site, current was passed through the electrodes that remained in the brain to produce a small lesion. Following transcardial perfusion with normal salinc and $10 \%$ formalin, brains werc removed from the lesioned animals. Brain tissue was subsequently frozen, sectioned, and stained with cresyl violet for histological analysis.

Behavior. Individual items of each drug-specific behavioral response were recorded for $1 \mathrm{~min}$ intervals every $10 \mathrm{~min}$ beginning immediately following systemic drug administration or onset of the intraneostriatal drug infusion. Locomotion, sniffing, rearing, repetitive head movements, and vacuous chewing were rated according to their intensity $(0$ $=$ not present, $1=$ mild, $2=$ moderate, $3=$ extreme $)$ and duration $(1$ $=$ discontinuous, 2 =continuous) during each observation period. These ratings were multiplied to yield a single value (e.g., the maximum score at each observation interval is $3 \times 2$ ), as previously described (Rebec et al., 1982). The behavioral score for each individual item of behavior reflects the average score across each of the $10 \mathrm{~min}$ observation periods.

Drugs. D-Amphetamine sulfate (Sigma), L-glutamate (Sigma), L-homocysteic acid (Sigma), CPPene (Sandoz), and dizocilpine (RBI) were mixed in $0.9 \%$ saline. Amphetamine was mixed as the free base; all other drugs were expressed as the salt.

Statistics. Voltammograms were expressed as the percentage baseline response at each $10 \mathrm{~min}$ interval following drug treatment. Mixedfactors analyses of variance were performed on all data. The drug treatments and the 10 min intervals served as the between- and withinsubjects factors, respectively. Further pairwise comparisons were assessed with Fisher's least significant difference (LSD).

\section{Results}

All lesions marking our voltammetric recording sites were located in the anterior neostriatum, approximately $2.5 \mathrm{~mm}$ lateral to the midline and $4.0-5.0 \mathrm{~mm}$ ventral to the brain surface. Similar to previous findings (Ewing et al., 1982; Pierce et al., 1992a), basal extracellular ascorbate levels, based on postcalibration values, did not differ between the intact/sham (238 \pm $20 \mu \mathrm{M}, n=13)$ and 6-OHDA (265 $\pm 44 \mu \mathrm{M}, n=6)$ groups. These values are comparable with those reported in previous studies (Gonon et al., 1980; Schenk et al., 1982; Wightman et al., 1987; Basse-Tomusk and Rebec, 1991). Based on postcalibration data, the level of basal neostriatal DOPAC recorded from intact/sham animals (20.7 $\pm 1.9 \mu \mathrm{M}, n=13)$ was similar
GLUTAMATE INFUSION

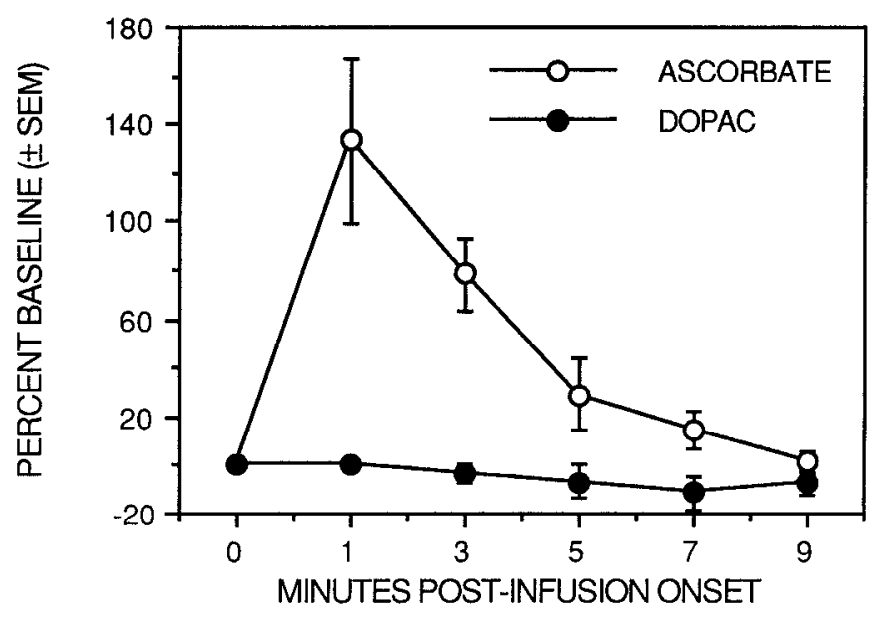

HOMOCYSTEIC ACID INFUSION

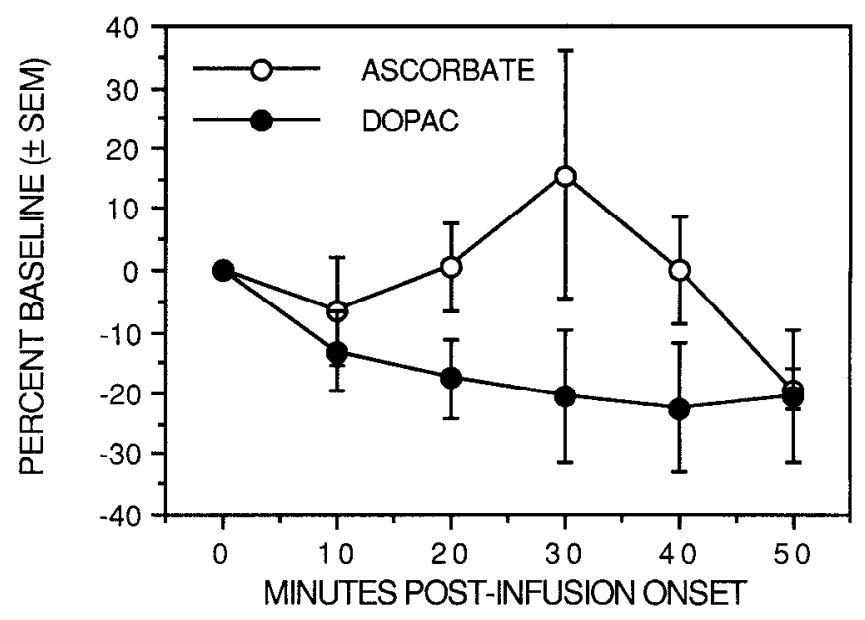

Figure 2. Effects of the infusion $(10 \mu \mathrm{l} / \mathrm{hr}$ for the duration of the experiment) of glutamate ( $1 \mu \mathrm{g} / \mu \mathrm{l} ; t o p)$ and the glutamate reuptake blocker homocysteic acid $(10 \mu \mathrm{g} / \mu \mathrm{l} ;$ bottom $)$ into the neostriatum on neostriatal ascorbate and DOPAC. Responses are as presented in Figure 1. Note the sharp, but transient, increase in neostriatal ascorbate release immediately following glutamate infusion onset and the lack of an effect on neostriatal DOPAC. Conversely, homocysteic acid infusions did not significantly alter neostriatal ascorbate or DOPAC.

to that reported elsewhere (Schenk et al., 1982; Basse-Tomusk and Rebec, 1991; Picrce and Rebec, 1992). Convcrscly, there was no detectable DOPAC peak following 6-OHDA treatment, suggesting a greater than $95 \%$ destruction of dopaminergic afferents in these animals (Zigmond et al., 1990; Hollerman et al., 1992). Basal neostriatal ascorbate and DOPAC did not differ significantly between the intact and sham groups; therefore, these groups were combined for comparison to 6-OHDA-lesioned animals.

\section{Effects of intraneostriatal saline and glutamate agonists on neostriatal ascorbate and DOPAC}

As depicted in Figure 1, intraneostriatal infusions of saline produced a slight decrease in neostriatal ascorbate and DOPAC in both the intact/sham and 6-OHDA-lesioned groups. These values served as the control comparisons for all of the following intact/sham and 6-OHDA-lesioned infusion groups, respec- 

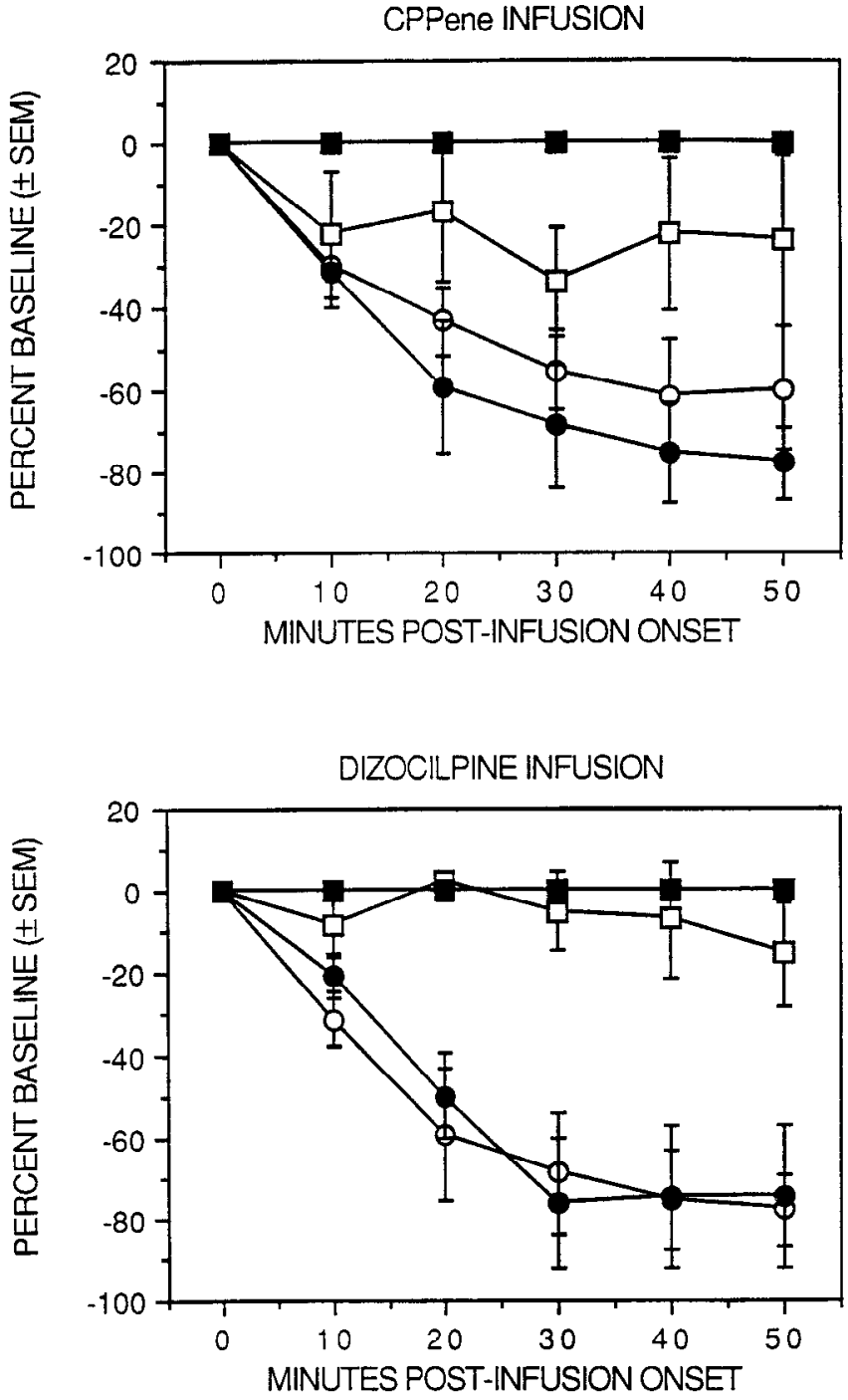

Figure 3. Effects of the infusion $(10 \mu \mathrm{l} / \mathrm{hr}$ for the duration of the experiment) of the competitive NMDA antagonist CPPene $(10 \mu \mathrm{g} / \mu \mathrm{l} ;$ top $)$ and the noncompetitive NMDA antagonist dizocilpine $(3 \mu \mathrm{g} / \mu \mathrm{l} ;$ bottom $)$ into the neostriatum of intact/sham and 6-OHDA-lesioned animals on neostriatal ascorbate and DOPAC. Responses and legend are as presented in Figure 1. Note the decrease in neostriatal ascorbate that occurred over the $50 \mathrm{~min}$ recording period in both intact $/ \mathrm{sham}$ and 6-OHDA-lesioned animals.

tively. The responses of intact and sham-lesioned animals following saline (as well as all drug administrations) were not significantly different. Therefore, these groups were combined for comparison to the 6-OHDA group in all of the following experiments.

As expected, intraneostriatal infusions of glutamate $(1 \mu \mathrm{g} / \mu \mathrm{l})$ produced a sharp, yet transient, increase in the extracellular level of neostriatal ascorbate $(p<0.0001)$. Conversely, infusion of the nonselective reuptake blocker homocysteic acid $(10 \mu \mathrm{g} / \mu \mathrm{l})$ did not significantly alter extracellular ascorbate in the neostriatum. Neither glutamate nor homocysteic acid infusions, however, produced significant changes in DOPAC. The results of these infusion experiments are summarized in Figure 2. Because glutamate and homocysteic acid are potentially neurotoxic, histologies were closely examined. In no case, however, was there evidence of gliosis other than that typically observed along the electrode tract.
SYSTEMIC DIZOCIPLINE-GLUTAMATE INFUSION

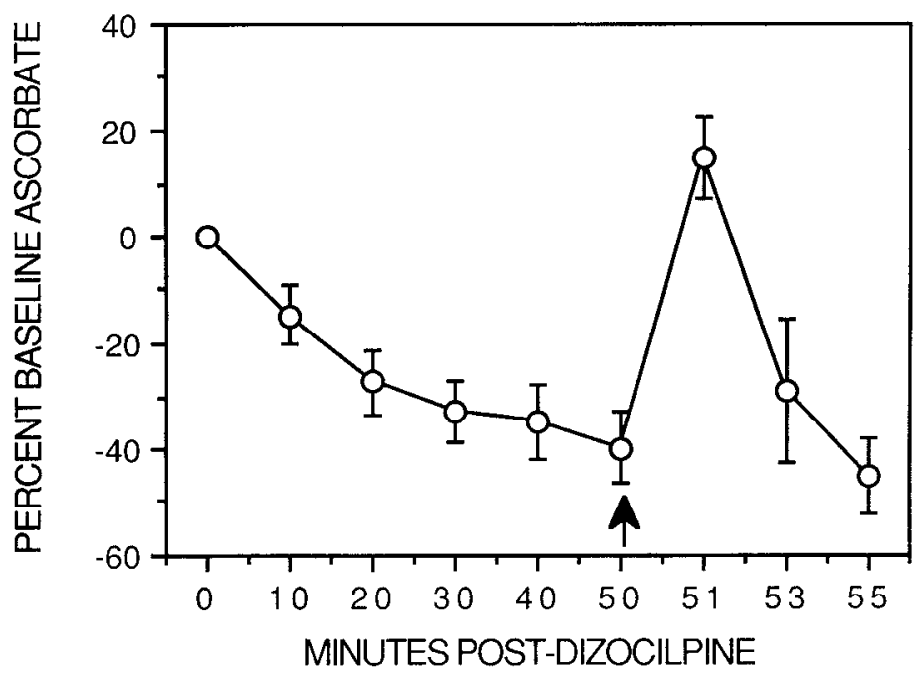

Figure 4. Effects of intraneostriatal glutamate $(1 \mu \mathrm{g} / \mu \mathrm{l})$ infusion (at arrow) into the neostriatum of animals in which dizocilpine $(1 \mathrm{mg} / \mathrm{kg})$ was administered $50 \mathrm{~min}$ previously on neostriatal ascorbate. Responses are as presented in Figure 1. Note the decrease in neostriatal ascorbate over the $50 \mathrm{~min}$ period following the systemic administration of dizocilpine. Note also the increase in neostriatal ascorbate in these same animals following the intraneostriatal administration of glutamate. This glutamate-induced ascorbate release is similar in magnitude and time course to that observed in undrugged animals (see Fig. 2, top).

\section{Effects of intraneostriatal NMDA antagonists on neostriatal ascorbate and DOPAC}

As shown in Figure 3, intraneostriatal administration of CPPene $(10 \mu \mathrm{g} / \mu \mathrm{l})$ or dizocilpine $(3 \mu \mathrm{g} / \mu \mathrm{l})$ significantly decreased ascorbate but had no effect on DOPAC in the neostriatum of both the intact/sham and 6-OHDA groups during the $50 \mathrm{~min}$ recording period $(p<0.0001)$. It is unlikely that the observed effects on ascorbate or behavior (see below) were due to diffusion of the drug up the infusion cannula since dizocilpine $(3 \mu \mathrm{g} / \mu \mathrm{l})$ infusions into cortex ( $3 \mathrm{~mm}$ ventral to dura) just dorsal to the neostriatal recording site produced no effect on either neostriatal ascorbate or behavior ( $n=2$; data not shown).

\section{Effects of intraneostriatal glutamate infusion following systemic dizocilpine}

In order to assess the effects of NMDA antagonism on the ability of glutamate to increase neostriatal ascorbate, glutamate $(1 \mu \mathrm{g} /$ $\mu$ ) was infused into the neostriatum $50 \mathrm{~min}$ after systemic administration of dizocilpine $(1 \mathrm{mg} / \mathrm{kg}$ ). As shown in Figure 4, subcutaneous dizocilpine significantly decreased neostriatal ascorbate $(p<0.0001)$. The subsequent infusion of glutamate into the neostriatum resulted in a frank, short-lived increase in neostriatal ascorbate similar to that produced by glutamate infusions into the neostriatum of undrugged animals.

\section{Effects of systemically administered dizocilpine on neostriatal ascorbate and DOPAC in intact/sham and SNR-lesioned animals}

Consistent with previous reports (Weihmuller et al., 1991; Pierce and Rebec, 1992), systemically administered dizocilpine significantly decreased neostriatal ascorbate while increasing extracellular concentrations of neostriatal DOPAC $(p<0.0001)$. As shown in Figure 5, whereas unilateral lesions of the SNR 

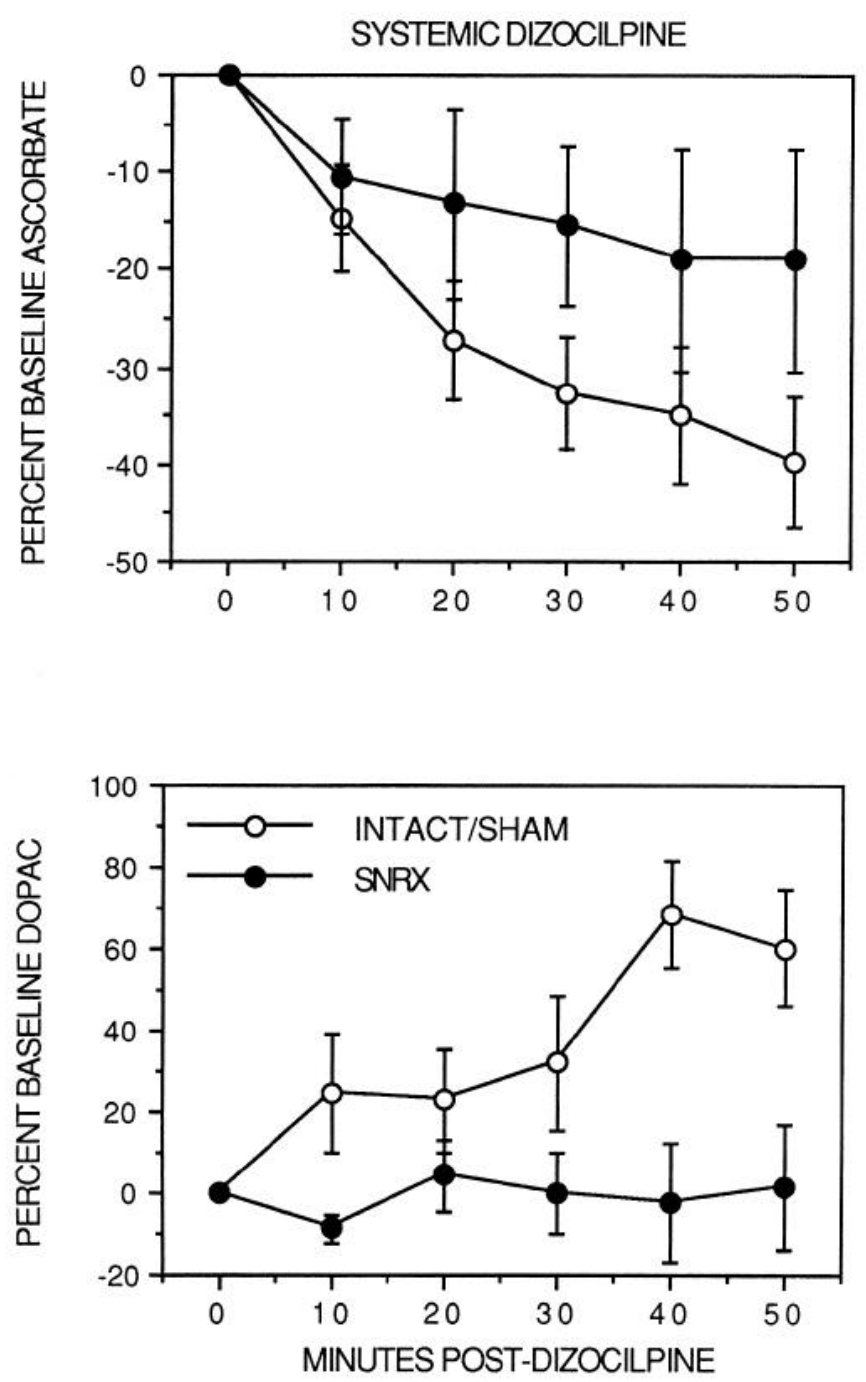

Figure 5. Effects of electrolytic SNR lesions (SNRX) on systemic (1 $\mathrm{mg} / \mathrm{kg}$ ) dizocilpine-induced decreases in neostriatal ascorbate (top) and increases in neostriatal DOPAC (bottom). Note that SNR lesions had no effect on dizocilpine-induced decreases in neostriatal ascorbate but completely abolished the ability of dizocilpine to increase extracellular levels of neostriatal DOPAC. did not significantly alter dizocilpine-induced decreases in neostriatal ascorbate, this lesion completely abolished the ability of dizocilpine to increase neostriatal DOPAC. Figure 6 depicts the typical extent of damage following a unilateral electrolytic lesion of the SNR. In all cases, approximately $70 \%$ of the SNR was damaged. SNR lesions did not, however, significantly affect the substantia nigra pars compacta, as demonstrated upon histological examination as well as through examination of extracellular neostriatal DOPAC levels. Thus, neostriatal DOPAC concentrations did not differ between SNR-lesioned (19.8 \pm 3.1 $\mu \mathrm{M}, n=4)$ and intact/sham (20.7 $\pm 1.9 \mu \mathrm{M}, n=13)$ animals. SNR lesions did, however, reduce neostriatal ascorbate somewhat (SNR-lesioned, $170 \pm 20 \mu \mathrm{M}, n=3$, vs intact/sham, 238 $\pm 20 \mu \mathrm{M}, n=13)$ even though this difference was not statistically significant.

\section{Effects of glutamate agonist and antagonist administration on individual items of behavior}

As shown in Table 1, intraneostriatal saline produced no behavioral activation. These results parallel previous reports that rats habituated to the behavioral arena show no behavioral response to systemic saline injections (Pierce and Rebec, 1990; Pierce et al., 1992a). Intraneostriatal administration of glutamate or homocysteic acid also failed to elicit behavioral activity (data not shown). Conversely, Table 1 indicates consistent behavioral activation during intraneostriatal infusion of dizocilpine or CPPene. Elevated sniffing $(p<0.001)$ and repetitive head movements $(p<0.0001)$ were most prominent, though increased locomotion $(p<0.0001)$ and chewing $(p<0.001)$ also were observed in both intact/sham and 6-OHDA-lesioned animals. Behavioral increases were evident in each case at 10 $20 \mathrm{~min}$ following infusion onset, and they persisted for the entire observation period $(50 \mathrm{~min})$. These behavioral effects were similar to those observed following the systemic administration of dizocilpine (Table 1).

\section{Discussion}

Our results demonstrate that (1) neostriatal ascorbate release is linked to the glutamate reuptake site and is influenced by neostriatal NMDA receptors, (2) the relationship between glutamate and ascorbate has functional consequences in that blockade of
Figure 6. Photomicrograph of a coronal section (approximately $5.5 \mathrm{~mm}$ posterior to bregma) through the SNR of an electrolytically lesioned animal. Note the damage to approximately $70 \%$ of the SNR with virtually no damage in the substantia nigra pars compacta.

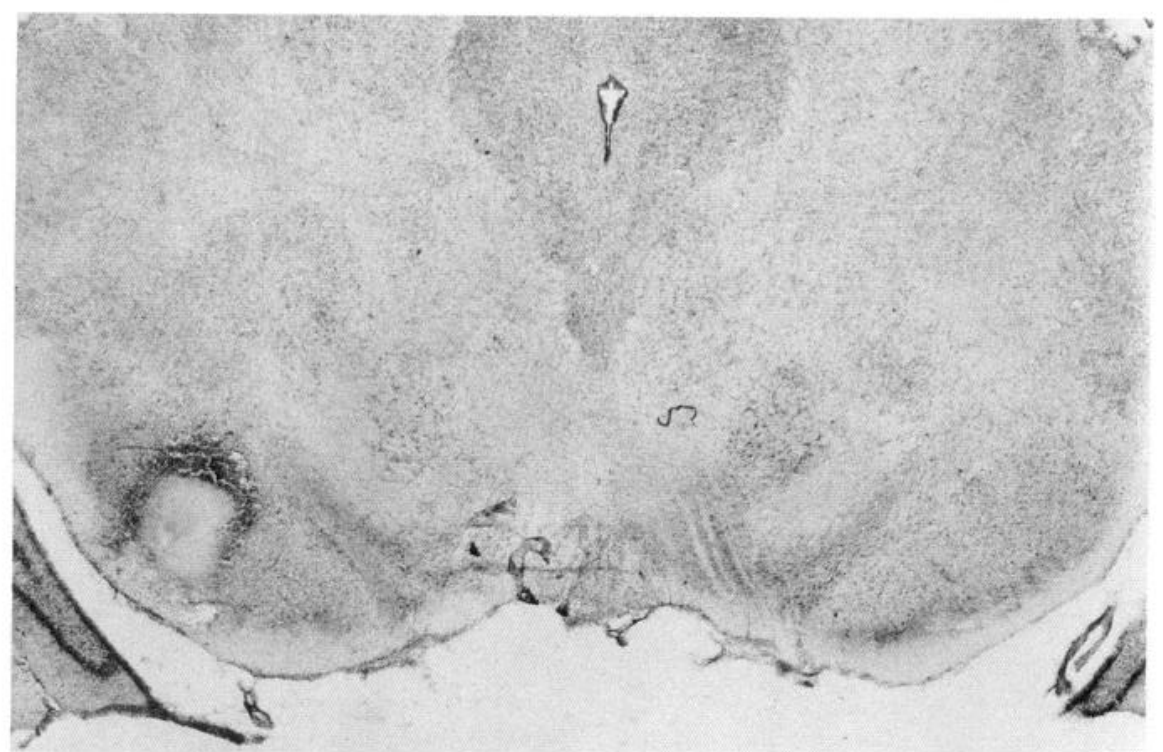


Table 1. Behavioral responses following intraneostriatal or systemic drug administration

\begin{tabular}{|c|c|c|c|c|c|}
\hline \multirow[b]{2}{*}{$\begin{array}{l}\text { Drug } \\
\text { treatment }\end{array}$} & \multicolumn{5}{|c|}{ Behavior scores } \\
\hline & Locomotion & Sniffing & Rearing & $\begin{array}{l}\text { Repetitive } \\
\text { head } \\
\text { movements }\end{array}$ & Chewing \\
\hline Saline/6-OHDA saline & $0 \quad(0)$ & $0 \quad(0)$ & $0 \quad(0)$ & $0 \quad(0)$ & $(0)$ \\
\hline CPPene & $0.25(0.25)$ & $0.75(0.48)$ & $0 \quad(0)$ & $1.0(0.41)^{*}$ & $1.25(0.48)^{*}$ \\
\hline 6-OHDA-CPPene & $1.25(0.48)^{*}$ & $1.75(0.85)^{*}$ & $0.5(0.5)$ & $1.5(0.96)^{*}$ & (0) \\
\hline Dizocilpine & $1.75(0.85)^{*}$ & $2.25(0.63)^{*}$ & $0 \quad(0)$ & $2.0(0)^{*}$ & (0) \\
\hline 6-OHDA-dizocilpine & $2.5(0.29)^{*}$ & $1.75(0.25)^{*}$ & $0.5(0.29)$ & $2.0(0)^{*}$ & $1.0(0.41)^{*}$ \\
\hline Systemic dizocilpine & $0.25(0.25)$ & $1.5(0.29)^{*}$ & $0 \quad(0)$ & $1.75(0.25)^{*}$ & $0.75(0.48)$ \\
\hline
\end{tabular}

Data are presented as the mean interval score ( \pm SEM) for individual items of behavior (see text for details).

${ }^{*} p<0.05$ versus saline/6-OHDA saline (Fisher's LSD).

neostriatal NMDA receptors both decreases neostriatal ascorbate and increases behavioral activation, and (3) NMDA antagonist-induced reductions in ascorbate release and increases in behavioral activity are not dependent on forebrain dopamine release. However, systemic administration of an NMDA antagonist reliably increases neostriatal DOPAC. This effect appears to be mediated by midbrain NMDA receptors since SNR lesions completely abolished this effect. Taken together, these results suggest that neostriatal ascorbate may act via glutamatergic mechanisms to influence neostriatal function and, furthermore, that the net effect of neostriatal glutamate release is the inhibition of basal ganglia motor output.

\section{Ascorbate-glutamate heteroexchange: influence of $N M D A$ receptors}

Our results confirm previous reports (O'Neill et al., 1984; Cammack et al., 1991; Ghasemzedah et al., 1991) that infusions of glutamate into the neostriatum elevate neostriatal ascorbate release. The link between ascorbate and glutamate has been suggested to occur via an active heteroexchange process at the glutamate reuptake site. This position is supported by evidence that hippocampal glutamate-induced ascorbate release is not only dose dependent but also completely inhibited by the coadministration of the glutamatc rcuptakc blockers homocysteic acid and D,L-threo- $\beta$-hydroxy-aspartic acid (Cammack et al., 1991). In addition, coadministration of the nonselective glutamate antagonist kynurenic acid has no effect on glutamateinduced increases in hippocampal ascorbate (Cammack et al., 1991). Thus, glutamate-induced increases in extracellular ascorbate release appear to be mediated by the glutamate reuptake site, and this effect is independent from the influence of glutamate receptors.

Recent evidence, however, suggests that the NMDA glutamate receptor may play a role in the regulation of neostriatal ascorbate release. We have shown, for example, that systemic administration of dizocilpine significantly decreases neostriatal ascorbate and attenuates amphetamine-induced ascorbate release (Pierce and Rebec, 1992). Furthermore, our present results show that intraneostriatal administration of either competitive (CPPcnc) or noncompetitive (dizocilpine) NMDA antagonists sharply reduce extracellular neostriatal ascorbate levels. Reconciling these data with the heteroexchange hypothesis of ascorbate release requires an understanding of the somewhat unique effects of stimulating terminal glutamate receptors. Thus, unlike striatal dopamine terminal receptors, which attenuate dopamine synthesis and release (Chesselet, 1984; Drukarch and Stoof,
1990), terminal NMDA and non-NMDA glutamate receptors actually facilitate glutamate release (Ferkany et al., 1982; Collins et al., 1983; Ferkany and Coyle, 1983), while increasing glutamate terminal excitability (Garcia-Munoz et al., 1991, 1992). This presynaptic positive feedback mechanism has been suggested to contribute to glutamate-induced neurotoxicity as well as the induction of long-term potentiation (Biziere and Coyle, 1978; Garcia-Munoz ct al., 1992). Thus, blockade of this presynaptic positive feedback via NMDA antagonists should result in decreased glutamate release. If neostriatal ascorbate and glutamate release are coupled via a carrier-mediated heteroexchange process, then it is not surprising that NMDA antagonists, which would decrease glutamate release, also would decrease ascorbate release as demonstrated in our present experiments. It also is possible, however, that antagonism of NMDA receptors located postsynaptically on striatal output neurons could inhibit the activity of the corticoneostriatal pathway, and thus the release of both neostriatal glutamate and ascorbate, via feedback through a striato-nigro-thalamo-cortico-striatal feedback loop (see Basse-Tomusk and Rebec, 1990; Pierce et al., 1992a). It is unlikely that this "long-loop" plays a primary role in NMDA antagonist-induced decreases in neostriatal ascorbate since in the present experiments substantia nigra lesions did not significantly inhibit the ability of dizocilpine to decrease ncostriatal ascorbate.

In order to assess the relationship between glutamate receptors and glutamate-induced neostriatal ascorbate release, we infused glutamate into the neostriatum of animals pretreated with a systemic injection of dizocilpine. Consistent with previous results (Pierce and Rebec, 1992), systemic dizocilpine significantly decreased basal neostriatal ascorbate $50 \mathrm{~min}$ after its administration. The subsequent infusion of glutamate into the neostriatum, however, resulted in a sharp increase in neostriatal ascorbate similar to the glutamate response observed in undrugged animals. Thus, while NMDA receptors may regulate basal ascorbate levels, NMDA receptor antagonism does not influence the ability of glutamate to increase extracellular ascorbate levels.

\section{Ascorbate-glutamate interactions: influence on behavior}

Besides decreasing neostriatal ascorbate, systemic administration of dizocilpine also has been shown to produce a characteristic behavioral syndrome characterized by stereotypy, hyperlocomotion, and ataxia (Koek et al., 1988; Carlsson and Svensson, 1990; Loscher and Honack, 1992; Pierce and Rebec, 1992). Hyperactivity also has been observed following the in- 
fusion of NMDA antagonists into the neostriatal complex. Thus, intraneostriatal administration of AP-5 induced sniffing stereotypy (Schmidt, 1986), while intra-accumbens infusions of this NMDA antagonist produced pronounced locomotor stimulation (Svensson and Carlsson, 1992). Our results confirm and extend these findings. We found, for example, that intraneostriatal administration of dizocilpine or CPPene produces a marked increase in a variety of behaviors, most notably locomotion, sniffing, head bobbing, and chewing. Our results also support suggestions that NMDA antagonists stimulate behavior independently from an action on the dopamine system (Carlsson and Carlsson, 1990; Carlsson et al., 1991; Svensson et al., 1991). That is, intraneostriatal dizocilpine and CPPene stimulated behavior without producing an effect on neostriatal DOPAC. Furthermore, intrancostriatal NMDA antagonist administration caused behavioral activation in animals with near-total depletions of striatal dopamine following 6-OHDA administration into the medial forebrain bundle. In fact, there was a slight increase in overall behavioral activation in 6-OHDA-lesioned animals relative to controls, particularly in the CPPene groups. Taken together, these results suggest that NMDA antagonistinduced hyperactivity is mediated in the neostriatum through a nondopaminergic mechanism.

It is likely that the NMDA antagonist-induced depletion of neostriatal ascorbate also contributed to the behavioral effects of these drugs. Ascorbate, for instance, could interact with the corticoneostriatal glutamate system to influence behavior. Thus, increases in neostriatal ascorbate should reverse the action of the glutamate reuptake site if, as recent evidence suggests, glutamate and ascorbate are linked via a heteroexchange process (see above). Ascorbate depletions following NMDA antagonist administration, therefore, should inhibit glutamate release, resulting in increased behavioral hyperactivity through disinhibition. Ascorbate also appears to have a more direct influence on neostriatal transmitter systems. Thus, ascorbate has been shown to inhibit NMDA receptor function (Majewska et al., 1990) and the binding of dopamine agonists and antagonists to $\mathrm{D}_{1}$ and $\mathrm{D}_{2}$ dopamine receptors (Hadjiconstantinou and Neff, 1983; Tolbert et al., 1992). Based on these lines of evidence, it is not surprising that fluctuations in neostriatal ascorbate influence behavior. In fact, increases in extracellular neostriatal ascorbate are known to attenuate the behavioral response to amphetamine and to potentiate the catalepsy produced by haloperidol (Rebec et al., 1985; White et al., 1990). Collectively, these results suggest that increased neostriatal ascorbate concentrations inhibit behavioral activation either presynaptically through interactions with the corticoncostriatal glutamate system or postsynaptically through some as yet undetermined interaction with glutamate and/or dopamine receptors.

\section{Glutamatergic control of nigrostriatal dopamine synthesis and release}

It has been shown that systemic administration of dizocilpine significantly incrcases cxtraccllular lcvels of neostriatal DOPAC and dopamine (Rao et al., 1990; Weihmuller et al., 1991; Miller et al., 1992; Pierce and Rebec, 1992), although the effects of dizocilpine on DOPAC, which mainly reflects alterations in dopamine synthesis (Zetterstrom et al., 1988), are much more pronounced than on dopamine itself (Weihmuller et al., 1991). Our present findings demonstrate that dizocilpine-induced increases in neostriatal DOPAC are not mediated exclusively by mechanisms intrinsic to the neostriatum. Thus, intraneostriatal administration of dizocilpine at a dose that produced alterations in behavior did not affect extracellular neostriatal DOPAC levels. Electrolytic lesions of the SNR, however, completely abolished the ability of systemically administered dizocilpine to increase neostriatal DOPAC. It is conceivable, therefore, that dizocilpine-induced increases in dopamine synthesis, as measured by neostriatal DOPAC formation, are regulated by NMDA receptors in the SNR. This hypothesis is consistent with preliminary data that intranigral, but not intraneostriatal, infusions of dizocilpine increase neostriatal dopamine release (Miller et al., 1992).

Alternatively, the SNR may regulate dopaminergic activity as part of a complex feedback system that receives inputs from a large number of forebrain regions rich in NMDA receptors. According to this model, dopaminergic activity may change only when a sufficient number of these receptors are blocked. Indeed, systemic, but not iontophoretic, administration of dizocilpine elevates the overall firing rate of midbrain dopaminergic neurons, and this effect is blocked by a hemitransection of descending forebrain efferents, many of which project to SNR (Zhang et al., 1992). Thus, SNR lesions would be expected to abolish the increase in dopaminergic activity produced by systemic dizocilpine, and to the extent that neostriatal DOPAC parallels dopamine, our results support this vicw. Morcover, rather than acting as the sole NMDA-rich forebrain region controlling dopaminergic activity via descending feedback loops, the neostriatum may share in this function with the nucleus accumbens, frontal cortex, and other relevant areas. Thus, although a failure of intraneostriatal infusions of dizocilpine to elevate DOPAC argues against an exclusive role for neostriatal NMDA receptors in the control of dopaminergic activity, our results do not rule out the participation of other forebrain regions. It appears, therefore, that the mechanisms by which glutamate receptors regulate the activity of ascending dopaminergic neurons are complex and require further research on both the processes within the substantia nigra as well as forebrain areas outside the neostriatum.

\section{Conclusions}

Our results demonstrate a functional relationship betwecn ncostriatal ascorbate and glutamate independent from the influence of neostriatal dopamine. That is, neostriatal ascorbate appears to act, either primarily or in part, via glutamatergic mechanisms to influence neostriatal function. Moreover, ascorbate influences neostriatal glutamate transmission presynaptically via an ascorbate-glutamate heteroexchange at the glutamate reuptake site and perhaps postsynaptically via NMDA receptor blockade (Majewska et al., 1990). In view of recent reports of a glutamate deficiency in schizophrenia (Deutch et al., 1989; Carlsson and Carlsson, 1990) coupled with evidence that ascorbate may serve as an effective adjunct treatment (Kanofsky et al., 1989; Suboticanec et al., 1990), further elucidation of the mechanisms underlying an ascorbate-glutamate interaction promises to shed light on what appears to be an important neurochemical component of complex behavioral activity.

\section{References}

Barbeito L, Cheramy A, Godeheu G, Desce JM, Glowinski J (1990) Glutamate receptors of a quisqualate-kainate subtype are involved in the presynaptic regulation of dopamine release in the cat caudate nucleus in vivo. Eur J Neurosci 2:304-311.

Basse-Tomusk A, Rebec GV (1990) Corticostriatal and thalamic reg- 
ulation of amphetamine-induced ascorbate release in the neostriatum. Pharmacol Biochem Behav 35:55-60.

Basse-Tomusk A, Rebec GV (199l) Regional distribution of ascorbate and 3,4-dihydroxyphenylacetic acid (DOPAC) in rat striatum. Brain Res 538:29-35.

Biziere K, Coyle JT (1978) Influence of cortico-striatal afferents on striatal kainic acid neurotoxicity. Neurosci Lett 8:303-310.

Cammack J, Ghasemzedeh B, Adams RN (1991) The pharmacological profile of glutamate-evoked ascorbic acid efflux measured by in vivo electrochemistry. Brain Res 565:17-22.

Carlsson M, Carlsson A (1990) Interactions between glutaminergic and monoaminergic systems within the basal ganglia-implications for schizophrenia and Parkinson's disease. Trends Neurosci 13:272276.

Carlsson M, Svensson A (1990) Interfering with glutamatergic neurotransmission by means of NMDA antagonist administration discloses the locomotor stimulatory potential of other transmitter systems. Pharmacol Biochem Behay 36:45-50.

Carlsson M, Svensson A, Carlsson A (1991) synergistic interactions between muscarinic antagonists, adrenergic agonists and NMDA antagonists with respect to locomotor stimulatory effects in monoaminedepleted mice. Naunyn Schmiedebergs Arch Pharmacol 343:568573.

Cespuglio R, Faradji H, Ponchon J-L, Riou F, Buda M, Gonon F, Pujol J-F, Jouvet $M$ (1981) In vivo measurement by differential pulse voltammetry of extracellular 5-hydroxyindoleacetic acid in the rat brain. J Physiol (Paris) 77:327-332.

Chesselet M-F (1984) Presynaptic regulation of neurotransmitter release in the brain: facts and hypothesis. Neuroscience 12:347-375.

Collins GGS, Anson J, Surtees L (1983) Presynaptic kainate and $\mathrm{N}$-methyl-D-aspartate receptors regulate excitatory amino-acid release in the olfactory cortex. Brain Res 265:157-159.

Crespi F, Sharp T, Maidement NT, Marsden CA (1984) Differential pulse voltammetry: simultaneous in vivo measurement of ascorbic acid, catechols and 5-hydroxyindoles in the rat striatum. Brain Res 332:135-138.

Deutch SI, Mastropaolo J, Schwartz BL, Rosse RB, Morihisa JM (1989) A "glutamatergic hypothesis" of schizophrenia. Clin Neuropharmacol 12:1-13.

Dorris RI, Dill RF. (1986) Potentiation of haloperidol-induced catalepsy by ascorbic acid in rats and nonhuman primates. Pharmacol Biochem Behav 24:781-783.

Drukarch B, Stoof JC (1990) D-2 dopamine autoreceptor selective drugs: do they really exist? Life Sciences 47:361-376.

Ewing AG, Wightman RM, Dayton MA (1982) In vivo voltammetry with electrodes that discriminate between dopamine and ascorbate. Brain Res 249:361-370.

Ferkany JW, Coyle JT (1983) Kainic acid selectively stimulates the release of endogenous amino acids. J Pharmacol Exp Ther 225:399406.

Ferkany KW, Zaczek R, Coyle JT (1982) Kainic acid stimulates excitatory amino acid neurotransmitter release at presynaptic receptors. Nature 298:757-759.

Ford LM, Norman AB, Sanberg PR (1989) The topography of MK801-induced locomotor patterns in rats. Physiol Behav 46:755-758.

Garcia-Munoz M, Young SJ, Groves PM (1991) Terminal excitability of the corticostriatal pathway. II. Regulation by glutamatc receptor stimulation. Brain Res 551:207-215.

Garcia-Munoz M, Young SJ. Groves PM (1992) Presynaptic longterm changes in excitability of the corticostriatal pathway. Neuroreport 3:357-360.

Gardiner TW, Armstrong-James M, Caan AW, Wightman RM, Rebec GV (1985) Modulation of neostriatal activity by iontophoresis of ascorbic acid. Brain Res 344:181-185.

Ghasemzedah B, Cammack J, Adams RN (1991) Dynamic changes in extracellular fluid ascorbic acid monitored by in vivo electrochemistry. Brain Res 547:162-166.

Gonon F, Buda M, Cespuglio R, Jouvet M, Pujol JF (1980) In vivo electrochemical detection of catechols in the neostriatum of anaesthetized rats: dopamine or DOPAC? Nature 286:902-904

Gonon F, Buda M, Cespuglio R, Jouvet M, Pujol JF (1981) Voltammetry in the striatum of chronic freely moving rats: detection of catechols and ascorbic acid. Brain Res 223:69-80.

Hadjiconstantinou M, Neff NH (1983) Ascorbic acid could be hazardous to your experiments: a commentary on dopamine receptor binding studies with speculation on a role for ascorbic acid in neuronal function. Neuropharmacology 22:939-943.

Hassler R, Haug P, Nitsch C, Kim JS, Paik K (1982) Effect of motor and premotor cortex ablation on concentrations of amino acids, monoamines, and acetylcholine and on the ultrastructure in rat striatum. A confirmation of glutamate as the specific cortico-striatal transmitter. J Neurochem 38:1087-1098.

Hiramatsu M, Cho A, Nabeshima T (1989) Comparison of the behavioral and biochemical effects of the NMDA receptor antagonists, MK-801 and phencyclidine. Eur J Pharmacol 166:359-366.

Hollerman JR, Abercrombie ED, Grace AA (1992) Electrophysiological, biochemical, and behavioral studies of acute haloperidol-induced depolarization block of nigral dopamine neurons. Neuroscience 47: 589-601.

Imperato A, Scrocco MG, Bacchi S, Angelucci L (1990) NMDA receptors and in vivo dopamine release in the nucleus accumbens and caudatus. Eur J Pharmacol 187:555-556.

Kamata K, Wilson RL, Alloway KD, Rebec GV (1986) Multiple amphetamine injections reduce the release of ascorbic acid in the neostriatum of the rat. Brain Res 362:331-338.

Kanofsky JD, Kay SR, Lindenmayer JP, Seifter E (1989) Ascorbate: an adjunctive treatment for schizophrenia. J Am Coll Nutr 8:425.

Keefe KA, Zigmond MJ, Abercrombie ED (1992) Extracellular dopamine in striatum: influence of nerve impulse activity in medial forebrain bundle and local glutamatergic input. Neuroscience 47:325332

Koek W, Woods JH, Winger GD (1988) MK-801, a proposed noncompetitive antagonist of excitatory amino acid neurotransmission, produces phencyclidine-like behavioral effects in pigcons, rats and rhesus monkeys. J Pharmacol Exp Ther 245:969-974.

Kretschmer BD, Zadow B, Volz TL, Volz L, Schmidt WJ (1992) The contribution of the different binding sites of the $N$-methyl-D-aspartate (NMDA) receptor to the expression of behavior. J Neural Transm 87:23-35.

Lehmann-Masten VD, Geyer MA (1991) Spatial and temporal patterning distinguishes the locomotor activating effects of dizocilpine and phencyclidine in rats. Neuropharmacology 30:629-636.

Leviel V, Gobert A, Guibert B (1990) The glutamate-mediated release of dopamine in the rat striatum: further characterization of the dual excitatory-inhibitory function. Neuroscience 39:305-312.

Loscher W, Honack D (1992) The behavioral effects of MK-801 in rats: involvement of dopaminergic, serotonergic and noradrenergic systems. Eur J Pharmacol 215:199-208.

Majewska MD, Bell JA, London ED (1990) Regulation of the NMDA receptor by redox phenomena: inhibitory role of ascorbate. Brain Res 537:328-332.

Miller DW, Anderson DR, Abercrombie ED (1992) MK-801 potentiates the $\mathrm{D}$-amphetamine-induced increase in striatal extracellular dopamine levels. Soc Neurosci Abstr 18:94.

Moghaddam B, Gruen RJ (1991) Do endogenous amino acids influence striatal dopamine release? Brain Res 544:329-330.

O'Neill RD, Fillenz M, Sundstrom, Rawlins NP (1984) Voltammetrically monitored brain ascorbate as an index of excitatory amino acid release in the unrestrained rat. Neurosci Lett 42:227-233.

Paxinos G, Watson C (1982) The rat brain in stereotaxic coordinates. New York: Academic.

Pierce RC, Rebcc GV (1990) Stimulation of both D1 and D2 receptors increases behavioral activation and ascorbate release in the neostriatum of freely moving rats. Eur J Pharmacol 191:295-302.

Pierce RC, Rebec GV (1992) Dopamine-, NMDA-, and sigma-receptor antagonists exert differential effects on basal and amphetamineinduced changes in neostriatal ascorbate and DOPAC in awake, behaving rats. Brain Res 579:59-66.

Pierce RC, Rowlett JK, Bardo MT, Rebec GV (1991) Chronic ascorbate potentiates the effects of chronic haloperidol on behavioral supersensitivity but not D2 dopamine receptor binding. Neuroscience 45:373-378.

Pierce RC, Miller DW, Reising DB, Rebec, GV (1992a) Unilateral neostriatal kainate, but not 6-OHDA, lesions block dopamine agonistinduced ascorbate release in the neostriatum of freely-moving rats. Brain Kes 597:139-I43.

Pierce RC, Wang Z, Heidenreich BA, Langley PE, Rebec GV (1992b) An easily fabricated electrode holder for voltammetric and electrophysiological recordings from awake, behaving rats. Kopf Carrier 32: $1-5$. 
Rao TS, Kim HS, Lehmann J, Martin LL, Wood P (1990) Interactions of phencyclidine receptor agonist MK-801 with dopaminergic system: regional studies in the rat. J Neurochem 54:1157-1162.

Rebec GV, Peirson EE, McPherson FA, Brugge K (1982) Differential sensitivity to amphetamine following long-term treatment with clozapine or haloperidol. Psychopharmacology 77:360-366.

Rebec GV, Centore JC, White LK, Alloway KD (1985) Ascorbic acid and the behavioral response to haloperidol: implications for the action of antipsychotic drugs. Science 227:438-440.

Rebec GV, Langley PE, Pierce RC, Wang Z, Heidenreich BA (1993) A simple micromanipulator for multiple uses in freely moving rats: electrophysiology, voltammetry, and simultaneous intracerebral infusions. J Neurosci Methods 47:53-59.

Schenk JO, Miller E, Gaddis R, Adams R (1982) Homeostatic control of ascorbate concentration in CNS extracellular fluid. Brain Res 253 353-356.

Schmidt WJ (1986) Intrastriatal injection of DL-2-amino-5-phosphonovaleric acid (AP-5) induces sniffing stereotypy that is antagonized by haloperidol and clozapine. Psychopharmacology 90:123130.

Suboticanec K, Folnegovic-Smalc V, Korbar M, Mestrovic B, Buzina R (1990) Vitamin C status in chronic schizophrenia. Biol Psychiatry 28:959-966.

Svensson A, Carlsson ML (1992) Injection of the competitive NMDA receptor antagonist AP-5 into the nucleus accumbens of monoaminedepleted mice induces pronounced locomotor stimulation. Neuropharmacology 31:513-518.

Svensson A, Carlsson M, Carlsson A (1991) Synergistic interactions between the NMDA antagonist dizocilpine and the preferential dopamine autoreceptor antagonists (+)-AJ 76 and (+)-UH 232 with regard to locomotor stimulation in monoamine-depleted mice. J Neural Transm 85:69-77.
Tolbert LC, Thomas TN, Middaugh LD, Zemp JW (1979) Effect of ascorbic acid on neurochemical, behavioral, and physiological systems mediated by catecholamines. Life Sci 25:2189-2195.

Tolbert LC, Morris PE, Spollen JJ, Ashe SC (1992) Stereospecific effects of ascorbic acid and analogues on D1 and D2 agonist binding. Life Sci 51:921-930.

Walaas I (1981) Biochemical evidence for overlapping neocortical and allocortical glutamate projections to the nucleus accumbens and rostral caudatoputamen in the rat brain. Neuroscience 6:399-405.

Weihmuller FB, O'Dell SJ, Cole BN, Marshall JF (1991) MK-801 attenuates the dopamine-releasing but not the behavioral effects of methamphetamine-an in vivo microdialysis study. Brain Res 549: 230-235.

White LK, Maurer M, Sidell EA, Kraft ME, Oh C, Rebec GV (1990) Intrastriatal infusions of ascorbate antagonize the behavioral response to amphetamine. Pharmacol Biochem Behav 36:485-489.

Wightman RM, Brown DS, Kuhr WG, Wilson RL (1987) Molecular specificity of in vivo electrochemical measurements. In: Voltammetry in the neurosciences (Justice J, cd), pp 103-138. Clifton, NJ: Iumana.

Young AMJ, Bradford HF (1986) Excitatory amino acid neurotransmitters in the corticostriate pathway: studies using intracerebral microdialysis in vivo. J Neurochem 47:1399-1404.

Zetterstrom T, Sharp T, Collin AK, Ungerstedt U (1988) In vivo measurement of extracellular dopamine and DOPAC in rat striatum after various dopamine-releasing drugs; implications for the origin of extracellular DOPAC. Eur J Pharmacol 148:327-334.

Zhang J, Chiodo LA, Freeman AS (1992) Electrophysiological effects of MK-801 on rat nigrostriatal and mesoaccumbal dopaminergic neurons. Brain Res 590:153-163.

Zigmond MJ, Abercrombie ED, Berger TW, Grace AA, Stricker EM (1990) Compensation after lesions of central dopaminergic neurons: some clinical and basic implications. Trends Neurosci 13:290-295. 